14 Slater A, Morison V. Selective adaptation cannot account for early infant habituation: a response to Dannemiller and Banks. Merrill-Palmer Quarterly habituation: a resp

15 Colombo J, Mitchell DW, Coldren JT, Freesman LJ. Individual differences in infant visual attention: are short lookers faster processors or feature processors? Child Dev 1991;62:1247-57.

16 Cohen LB. Examination of habituation as a measure of aberrant infant development. In: Friedman SL, Sigman M, eds. Preterm birth and psychological development. New York: Academic Press, 1981:241-53.

17 Friedman S. Infant habituation: process, problems, and possibilities. In: Ellis $\mathrm{N}$, ed. Aberrant development in infancy: human and animal studies. New York: Halstead Press, 1975:217-39.

18 Lester BM. Cardiac habituation of the orienting response to an auditory signal in infants of varying nutritional status. Dev Psychol 1975;11:432-42. Slater A. Individual differences in infancy and later IQ. F Child Psychol Psychiatry 1995;36:69-112.

20 Colombo J, Mitchell DW, O'Brien M, Horowitz FD. The stability of visual habituation during the first year of life. Child Dev 1987;58:474-87.

21 Pêcheux MG, Lécuyer R. A longitudinal study of visual habituation between 3, 5 and 8 months of age. Br f Dev Psychol 1989;7:159-69.
22 Rose DH, Slater AM, Perry H. Prediction of childhood intelligence from habituation in early infancy. Intelligence 1986;10:251-63.

23 McCall RB, Carriger MS. A meta-analysis of infant habituation and recognition memory performance as predictors of later IQ. Child Dev 1993;64:57-79.

24 Lécuyer R. Habituation and attention, novelty and cognition: where is the continuity? Hum Dev 1989;32:148-57.

25 Laucht M, Esser G, Schmidt M. Contrasting infant predictors of later cognitive functioning. I Child Psychol Psychiatry 1994;35:649-62.

26 Dougherty TM, Haith MM. Infant expectations and reaction time as predictors of childhood speed of processing and IQ. Dev Psychol 1997;33: $146-55$

27 Clarke A. Predicting human development: problems, evidence, implications. Bull Br Psychol Soc 1978;31:249-58.

$28 \mathrm{McC}$ all RB. Qualitative transitions in behavioral development in the first two years of life. In: Bornstein $\mathrm{MH}$, Kessen W, eds. Psychological development from infancy: image to intention. Hillsdale: Erlbaum Associates, 1979:183-224.

29 Cohen SE, Parmelee AH. Prediction of five-year Stanford-Binet scores in preterm infants. Child Dev 1983;54:1242-53.

\title{
Treatment of oesophageal varices
}

Bleeding from oesophageal varices is the most common cause of serious gastrointestinal haemorrhage in children. Bleeding may occur at any age, but some patients with varices never bleed. ${ }^{1}$ The risk of bleeding is not linearly related to portal pressure, but to the size of the varix and the thickness and integrity of its wall. ${ }^{2}$ Thus varices are most likely to bleed if they project prominently into the oesophageal lumen, if the overlying mucosa is blue, and particularly if there are 'cherry red spots' on the varix. Salicylate ingestion used to be recognised as an important precipitant.

The treatment of bleeding oesophageal varices is dependent on the underlying cause. In patients with portal hypertension from intrahepatic liver disease treatment is dictated by the latter and may determine the need for liver transplantation. Patients with good liver function and bleeding varices can, however, be successfully managed by treatment of their portal hypertension alone. Opinions on the primary management of extrahepatic portal hypertension have long been divided between those who advocate portosystemic shunting and those who favour endoscopic injection sclerotherapy. The results from studies of large series of children undergoing endoscopic injection sclerotherapy have encouraged the widespread acceptance of this technique in children with intrahepatic disease, in whom prognosis is determined more by underlying liver pathology, and in those with portal vein thrombosis or presinusoidal venous obstruction in whom variceal bleeding is the main threat to life..$^{3-5}$

The management of acute variceal bleeding involves prompt but careful resuscitation. Shock should be corrected by cautious blood transfusion, but over transfusion may increase splanchnic blood flow and precipitate rebleeding. Coagulopathy and severe thrombocytopenia (platelet count less than $50 \times 10^{9} / 1$ ) require correction and sepsis should be sought and treated with intravenous antibiotics. Patients must be monitored closely for continuing haemorrhage and the development of hepatic encephalopathy, and arrangements should be made for transfer to a centre where flexible fibreoptic endoscopy can be carried out by an operator skilled in injection sclerotherapy.

The use of somatostatin and its longer acting synthetic analogue octreotide has not been fully evaluated in children. In some adult studies these drugs have proved to be as effective as emergency sclerotherapy ${ }^{67}$ and balloon tamponade ${ }^{8}$ in controlling bleeding. Moreover, they are easily administered by continuous intravenous infusion and serious side effects are very rare. They may be particularly useful in stabilising a child before transfer or in preventing early rebleeding after sclerotherapy. ${ }^{9}$ As they are not effective in non-variceal gastrointestinal bleeding, ${ }^{10}$ diagnostic upper gastrointestinal endoscopy is essential.

Flexible fibreoptic endoscopy is ideally carried out under general anaesthesia with an endotracheal tube in situ within 24 hours of presentation. After assessment of the varices and the upper gastrointestinal tract, the varices are injected using a flexible endoscopic needle. Injections are concentrated at the cardia and in the lower $3 \mathrm{~cm}$ of the oesophagus (the site of perforating veins) and are predominantly intravariceal. The details of the technique and type of sclerosant have been reviewed elsewhere. ${ }^{11}$ Patients are given ranitidine and sucralfate by mouth for up to two weeks after each injection session and antibiotic prophylaxis is recommended for those with damaged/ prosthetic heart valves. The initial two or three treatments are performed at weekly intervals, but injection is deferred for one week if significant oesophageal mucosal ulceration is present. Further treatments are given at one to three monthly intervals until the varices have either disappeared or been converted into thrombosed cords. Most varices can be obliterated within one year by five to eight injection sessions. ${ }^{3}$ Regular checks, usually as a day case, are then carried out every six to 18 months until a stable state is achieved.

The efficacy of sclerotherapy in treating oesophageal varices is clearly shown by the King's College Hospital series of 108 children treated in the 1980 s. $^{3}$ Endoscopically confirmed obliteration of bleeding oesophageal varices was achieved in all children with portal vein obstruction and $84 \%$ of those with intrahepatic disease (for example, biliary atresia, congenital hepatic fibrosis, cystic fibrosis). All but one of the children whose varices were not obliterated did not complete a course of sclerotherapy because of liver transplantation or death from liver failure. Only one child died from variceal haemorrhage.

Injection sclerotherapy has been associated with numerous complications, ${ }^{11}$ but these are rarely serious in children. Transient fever and mild retrosternal discomfort are common sequelae after injection and are usually self limiting, but may signify bacteraemia. Gastrointestinal bleeding before variceal obliteration is complete occurs in $40 \%$ of patients ${ }^{3}$ and is usually due to a non-thrombosed varix or an oesophageal mucosal ulcer, but may be secondary to peptic ulceration. The short term incidence of recurrent oesophageal varices and bleeding from gastric varices is low $(<10 \%)$ and the former often respond to further sclerotherapy. ${ }^{3}$ In adults, sclerotherapy ulcers can be reduced by prophylactic ranitidine ${ }^{12}$ and the incidence of oesophageal strictures can be decreased by using smaller 
volumes of sclerosant and prophylactic sucralfate. ${ }^{13}$ Some children develop oesophageal dysmotility and gastrooesophageal reflux, which may cause intermittent dysphagia and heartburn. Systemic dissemination of the injected sclerosant leading to distant complications has been reported, but appears to be rare..$^{114}$

Little is known about the long term outcome of children after injection sclerotherapy for bleeding oesophageal varices. In those with cirrhosis, the long term outcome is jeopardised not only by the complications of portal hypertension, but also by deteriorating liver function. Treatment of bleeding oesophageal varices by sclerotherapy is effective in controlling haemorrhage and, unlike portosystemic shunting, does not reduce portal perfusion or carry the risk of encephalopathy. Moreover, it does not add to the technical difficulties of liver transplantation provided sclerotherapy is not carried out immediately before surgery. Those with serious underlying liver disease are, however, often best managed by liver transplantation. For children with extrahepatic portal hypertension, indications for surgery include uncontrollable variceal bleeding, bleeding from gastric or ectopic varices not accessible to sclerotherapy, lack of access to expert sclerotherapy, and severe symptomatic hypersplenism. ${ }^{15}$ In one study of 32 children with portal vein thrombosis followed up for a mean period of nine years after endoscopic variceal obliteration, recurrent variceal bleeding developed in 10 (31\%) patients, but half of these were effectively controlled by further sclerotherapy. ${ }^{14}$ Gastric variceal bleeding not amenable to sclerotherapy necessitated portosystemic shunt surgery in four $(13 \%)$ patients. Two patients required a splenectomy for symptomatic hypersplenism. Endoscopic injection sclerotherapy alone was safe and effective in controlling variceal bleeding from portal hypertension in the long term in over $80 \%$ of children with portal vein occlusion.

Two new treatments have affected the management of bleeding oesophageal varices, but their precise role in children has yet to be determined. The first is variceal band ligation, which has been adopted by many as the preferred method of endoscopic control of bleeding oesophageal varices in adults with cirrhosis. It achieves variceal obliteration more quickly, with a lower rebleeding rate than injection sclerotherapy, and complications such as oesophageal stricture may be reduced. ${ }^{16}{ }^{17}$ It is no more effective than sclerotherapy in controlling active haemorrhage, however, and recurrent varices may be more common. Preliminary clinical experience in children ${ }^{18} 19$ suggests that the technique is possible in those older than 2 years, but it is currently more cumbersome than sclerotherapy.

The transjugular intrahepatic portosystemic stent shunt is the second novel approach, whereby a stent is inserted between the portal and hepatic veins within the liver. This can be useful as a temporary measure in selected patients with complicated portal hypertension who are waiting for liver transplantation, but long term patency rates are unknown and reports to date simply suggest that it is a feasible option in some children. ${ }^{20}$

The role of $\beta$ blockers in children with portal hypertension remains uncertain. These drugs reduce portal venous inflow by decreasing cardiac output and by blocking $\beta$ receptors in the splanchnic vascular bed. In adults, trials with propranolol in patients who have already bled from varices have yielded mixed results and if there is a benefit, it is likely to be modest. ${ }^{21}$ Uncontrolled studies in children do no more than point to a possible role. ${ }^{22}$ Although $\beta$ blockers may be of value in primary or secondary prophylaxis, there is no good evidence to support prophylactic injection sclerotherapy. ${ }^{11}$

Department of Paediatric Surgery, Clarendon Wing,

MARK D STRINGER

Leeds General Infirmary, Belmont Grove,

Leeds LS2 9NS

St fames's University Hospital,

PATRICIA MCCLEAN

Beckett Street,

Leeds LS9 7 TF

1 Bernard O, Alvarez F, Brunelle F, Hadchouel P, Alagille D. Portal hypertension in children. Clin Gastroenterol 1985;14:33-55.

2 Dawson JL Oesophageal varices: curiosities. BMF 1983;286:826.

3 Howard ER, Stringer MD, Mowat AP. Assessment of injection sclerotherapy in the management of 152 children with oesophageal varices. $\mathrm{Br} F$ Surg 1988;75:404-8.

4 Maksoud JG, Goncalves MEP, Porta G, Miura I, Velhote MCP. The endoscopic and surgical management of portal hypertension in children: analysis of 123 cases. $\mathcal{F}$ Pediatr Surg 1991;26:178-81.

5 Paquet KJ, Lazar A. Current therapeutic strategy in bleeding esophageal varices in babies and children and long-term results of endoscopic paravariceal sclerotherapy over twenty years. Eur f Pediatr Surg 1994;4:16572 .

6 Shields R, Jenkins SA, Baxter JN, et al. A prospective randomised controlled trial comparing the efficacy of somatostatin with injection sclerotherapy in the control of bleeding oesophageal varices. f Hepatol 1992;16:128-37.

7 Sung JJY, Chung SCS, Lai CW, Chan FKL, Leung JWC, Yung MY. Octreotide infusion or emergency sclerotherapy for variceal haemorrhage. Lancet 1993;342:637-41.

8 Avgerinos A, Kionis C, Rekoumis G, Gaima P, Papadimitriou N, Raptis S. A prospective randomised trial comparing somatostatin, balloon tamponade and the combination of both methods in
variceal haemorrhage. $\mathcal{F}$ Hepatol 1991;13:78-83.

9 Bessan I, Ingraud P, Person B, et al. Sclerotherapy with or without octreotide for acute variceal bleeding. N Engl f Med 1995;333:555-60.

10 Christiansen J, Ottenjann R, Von Arx F. Placebo-controlled trial with the somatostatin analogue SMS 201-995 in peptic ulcer bleeding. Gastroenterology 1989;97:568-74.

11 Stringer MD, Howard ER. The role of endoscopic injection sclerotherapy in the management of portal hypertension in children. In: Howard ER, ed. Surgery of liver disease in children. Oxford: Butterworth-Heinemann, 1991:157-70.

12 Kumar A, Mehta SR, Joshi V, Kasthuri AS, Narayanan VA. Ranitidine for the prevention of complications following endoscopic sclerotherapy for esophageal varices. $\mathcal{F}$ Assoc Physicians India 1993;41:584-9.

13 Guady H, Rosman A, Korssen M. Prevention of stricture formation after endoscopic sclerotherapy of esophageal varices. Gastrointest Endosc 1989;35:377-80.

14 Stringer MD, Howard ER. Long term outcome after injection sclerotherapy for oesophageal varices in children with extrahepatic portal hypertension. for oesophageal varices

15 Heaton ND, Howard ER. Complications and limitations of injection sclerotherapy in portal hypertension. Gut 1993;34:7-10

16 Gimson AES, Ramage JK, Panos MZ, et al. Randomised trial of variceal banding ligation versus injection sclerotherapy for bleeding oesophageal varices. Lancet 1993;342:391-4.

17 Laine L, Cook D. Endoscopic ligation compared with sclerotherapy for treatment of esophageal variceal bleeding. A meta-analysis. Ann Intern Med 1995;123:280-7.

18 Cano I, Urruzuno P, Medina E, et al. Treatment of esophageal varices by endoscopic ligation in children. Eur F Pediatr Surg 1995;5:299-302.

19 Fox VL, Carr-Locke DL, Connors PJ, Leichtner AM. Endoscopic ligation of esophageal varices in children. F Pediatr Gastroenterol Nutr 1995;20:202-

20 Schweizer P, Brambs HJ, Schweizer M, Astfalk W. TIPS: a new therapy for esophageal variceal bleeding caused by EHBA. Eur 7 Pediatr Surg 1995;5:211-5.

21 Vickers C, Rhodes J, Chesner I, et al. Prevention of rebleeding from oesophageal varices: two-year follow-up of a prospective controlled trial of propranolol in addition to sclerotherapy. F Hepatol 1994;21:81-7.

22 Shashidhar H, Pizzi AM, Grand RJ, Langhans NA. Use of propranolol in prevention of portal hypertensive haemorrhage in children. Gastroenterology 1996;110:A838. 